\title{
Review: angiotensin receptor blockers do not reduce mortality or hospital admission rates in heart faillure
}

Jong P,Demers C, McKelvie RS, et al. Angiotensin receptor blockers in heart failure: meta-analysis of randomized controlled trials. J Am Coll Cardiol 2002 Feb 6;39:463-70.

\author{
QUESTION: In patients with heart failure (HF), do angiotensin receptor blockers (ARBs) \\ reduce mortality and hospital admission rates?
}

For correspondence: Dr P Liu, Heart E Stroke/Richard Lewar Centre of Excellence, Toronto, Ontario, Canada. peter.liu@utoronto.ca

\section{Data sources}

Studies were identified by searching Medline, EMBASE/ Excerpta Medica, Biological Abstracts, International Pharmaceutical Abstracts, Cochrane Controlled Trials Database, McMaster Cardiovascular Randomized Clinical Trial Registry, and Science Citation Index up to May 2001.

\section{Study selection}

Studies were selected if they were randomised controlled trials with blinding and at least 4 weeks of follow up that compared ARBs with either placebo or angiotensin converting enzyme inhibitors (ACEIs) in patients with New York Heart Association functional class II to IV HF and if they reported on mortality and hospital admission rates. Studies reported in non-peer reviewed journals were excluded.

\section{Data extraction}

Data were extracted independently by 2 reviewers on patient characteristics, drug type and dose, mean follow up, and outcomes.

\section{Main results}

17 trials (12 469 patients) met the selection criteria. All trials reported mortality rates; 1674 patients died. The ARB and control groups did not differ for mortality or hospital admission rates (reported in 6 trials) (table). None of the stratified analyses (ARBs $v$ placebo [7 trials], ARBs $v$ ACEIs [6 trials], ARBs and ACEIs in combination $v$ ACEIs alone $[6$ trials $]$ ) reached statistical significance for either outcome except for the combination of ARBs and ACEIs, which showed a benefit for reducing the hospital admission rate over ACEIs alone (table). The review had $90 \%$ power to detect an absolute risk reduction of $2.0 \%$ in all-cause mortality and a $2.4 \%$ reduction in the hospital admission rate with a type 1 error rate of $5 \%$

\section{Conclusion}

In patients with heart failure, angiotensin receptor blockers do not reduce mortality or hospital admission rates more than do angiotensin converting enzyme inhibitors or placebo.
Angiotensin receptor blockers (ARBS) v placebo or angiotensin converting enzyme inhibitors (ACEIs) in heart failure at 4 weeks to 1.5 years*

\begin{tabular}{lllll} 
Outcomes & ARBs & $\begin{array}{l}\text { ACEls or } \\
\text { placebo }\end{array}$ & RRR (95\% CI) & NNT (CI) \\
\hline Death & $13 \%$ & $15 \%$ & $4 \%(-19$ to 22$)$ & Not significant \\
\hline Hospital admission & $14 \%$ & $17 \%$ & $12 \%(-5$ to 27$)$ & Not significant \\
& ARBs and ACEls & ACEls & & \\
Hospital admission & $13 \%$ & $17 \%$ & $22 \%(12$ to 32$)$ & $26(19$ to 49$)$ \\
\hline
\end{tabular}

*Abbreviations defined in glossary; RRR, NNT, and $\mathrm{Cl}$ calculated from data in article by using random effects.

\section{COMMENTARY}

The initial success of ACEIs for reducing mortality in patients with HF caused by left ventricular systolic dysfunction has led to the search for even better formulations. The hypothesis that a better result could be obtained by agents that directly and specifically or more completely antagonise angiotensin II was appealing. How ACEIs actually reduce mortality is not fully understood. What if the other seemingly minor pathways blocked by ACEIs, which were theoretically responsible for their side effects, were an important component of their benefit?

The Evaluation of Losartan in the Elderly study (ELITE)- II $^{1}$ was designed to assess mortality differences between the ARB losartan and the ACEI captopril. Some commentators have been overly generous in suggesting that ELITE-II indicated that an ARB was equivalent to an ACEI. However, the data showed trends favouring the ACEI. So the best that could be said from ELITE-II was that an ARB was "not superior to" an ACEI.

Would patients benefit from having both types of medication? In the Valsartan Heart Failure Trial (Val-HeFT), ${ }^{2}$ an ARB was added to current treatment, which resulted in no change in overall mortality and a reduction in the number of hospital admissions caused by HF. However, benefit was markedly influenced by concomitant treatment. There was benefit when an ARB was added if patients were not receiving an ACEI or $\beta$ blocker, modest benefit if they were receiving an ACEI or a $\beta$ blocker but not both, and increased death and hospital admission if they were already receiving both an ACEI and a $\beta$ blocker.

The ELITE-II and Val-HeFT data are important here because their inclusion is the primary difference between the present meta-analysis by Jong et al and previous ones. Either of these trials dwarfs all previous trials combined. Since ELITE-II was done, practice guidelines have appropriately placed ACEIs as firstline treatment, with ARBs to be substituted if "intolerance" or "contraindication" exists. However, intolerance is most often mild, ameliorated with time, and often overcome when the patient understands how pivotal the ACEI is for their condition. ACEIs and ARBs have similar contraindications and adverse renal effects.

Dalane W Kitzman, MD Wake Forest University School of Medicine Winston-Salem, North Carolina, USA

1 Pitt B, Poole-Wilson PA, Segal R, et al. Effect of losartan compared with captopril on mortality in patients with symptomatic heart failure: randomised trial - the Losartan Heart Failure Survival Study ELITE II. Lancet 2000:355:1582-7.

2 Cohn JN, Tognoni G, for the Valsartan Heart Failure Trial Investigators. A randomized trial of angiotensin-receptor blocker valsartan in chronic heart failure. N Engl J Med 2001;345:1667-75. 